DOI: http://dx.doi.org/10.1590/fst.2014.0041

\title{
Effects of genotype and environment on grain yield and quality traits in bread wheat (T. aestivum $\mathrm{L}$.)
}

\author{
Yuksel KAYA $^{1,2 *}$, Mevlut AKCURA ${ }^{3}$
}

\begin{abstract}
Genotype (G), environment (E) and their interaction (GEI) play an important role in the final expression of grain yield and quality attributes. A multi-environment trial in wheat was conducted to evaluate the magnitude of $G$, E and GEI effects on grain yield and quality of wheat genotypes under the three rainfed locations (hereafter environment) of Central Anatolian Plateau of Turkey, during the 2012-2013 cropping season. Grain yield (GY) and analyses of test weight (TW), protein content (PC), wet gluten content (WGC), grain hardness (GH), thousand kernel weight (TKW) and Zeleny sedimentation volume (ZSV) were determined. Allelic variations of high and low molecular weight glutenin subunits (HMW-GS and LMW-GS) and $1 \mathrm{~B} / 1 \mathrm{R}$ translocation were determined in all genotypes evaluated. Both HMW-Glu-1, 17+18, 5+10 and LMW-Glu-3 b, b, $\mathrm{b}$ corresponded to genotypes possessing medium to good quality attributes. Large variability was found among most of the quality attributes evaluated; wider ranges of quality traits were observed in the environments than among the genotypes. The importance of the growing environment effects on grain quality was proved, suggesting that breeders' quality objectives should be adapted to the targeted environments.
\end{abstract}

Keywords: bread wheat; quality; genotype; environment; HMW-GS; LMW-GS.

\section{Introduction}

Development of wheat cultivars with good bread making quality is a challenging objective for many wheat breeding programs. The major wheat endosperm protein, the gluten, is responsible for bread making quality (Branlard \& Dardevet, 1985). Gluten is composed of two prolamine groups, gliadins, and glutenin. Glutenins consist of low- and high-molecularweight (LMW and HMW) complex subunits and constitute about $30-40 \%$ of flour protein. It has been reported that HMW glutenin subunits have the largest effect on bread making quality even though they constitute only $10 \%$ of the total storage proteins as compared to LMW, which contributes with $40 \%$. The HMW-GSs described as Glu-A1, Glu-B1, and Glu-D1 are encoded by multi-allelic genes located on the long arms of chromosomes 1A, 1B and 1D respectively (Payne et al., 1984). It has been reported that HMW-GSs are encoded by three loci, Glu-A1, Glu-B1, and Glu-D1 (Payne \& Lawrence, 1983). LMWGSs are encoded by three loci, Glu-A3, Glu-B3, and Glu-D3 (Gupta \& Shepherd, 1990).

Worldwide, the wheat-rye $1 \mathrm{~B} / \mathrm{lR}$ chromosome translocation is used because of the presence of genes for resistance to diseases. Unfortunately, wheat cultivars with $1 \mathrm{~B} / \mathrm{lR}$ translocation display poor bread making quality as a result of dough stickiness and poor mixing tolerance (Pena et al., 1990).

It is important to determine and quantify the extent to which factors like the environment (E) and genotype $\mathrm{x}$ environment interaction (GEI) contribute to variations in each wheat quality parameter. The influence of $\mathrm{E}$ on certain quality parameters vary, but it is generally stronger on PC and protein related parameters (Fowler \& De La Roche, 1975). In order to minimize the masking effect of GEI, breeders should determine a quality parameter or parameters that perform consistently in the Es (Lin \& Binns, 1994).

Plant breeders use heritability estimates to determine the influences of the environmental and genetic factors on the trait of interest and choose the selection procedure that should be implemented to make improvements. Heritability can be defined as the proportion of the observed variation in a progeny that is inherited (Poehlman \& Sleper, 2006). The extent to which replicated testing is required for selection will depend on the heritability estimate (Nyquist, 1991). This estimate gives plant breeders an understanding to what extent a trait is influenced by the $\mathrm{G}$ as opposed to $\mathrm{E}$.

Correlations, although reliable only for the range of material tested, may point to relationships that can be utilised in making a selection programme more effective (Baker et al., 1971). A correlation coefficient between two quality attributes that is unusually high suggests a strong heritable association and possibly a narrow gene base (Gaines, 1991).

The objectives of this research were i) to determine the relative contributions of G, E, and GEI to the variation in GY and quality traits of 20 wheat genotypes tested across three locations, ii) to analyze the relationships between GY and quality traits, iii) to identify high and low molecular weight glutenin subunits

\footnotetext{
Received 13 Mar., 2014

Accepted 03 Apr., 2014 (006318)

${ }^{1}$ Graduate School of Natural Sciences, Onsekiz Mart University, Canakkale, Turkey, e-mail: yuksel_k@yahoo.com

2 Bahri Dagdas International Agricultural Research Institute, Konya, Turkey

${ }^{3}$ Field Crops Department, Agricultural Faculty, Onsekiz Mart University, Canakkale, Turkey

${ }^{*}$ Corresponding author
} 
(HMW-GS and LMW-GS) associated with quality traits, and iv) to find the best wheat genotypes based on GY and quality traits.

\section{Material and method}

\subsection{Genotype characteristics}

Among the 20 genotypes tested across three environments, G1 (Gerek-79), G2 (Karahan-99), G3 (Sonmez-01), G4 (Mufitbey), and G5 (Bayraktar) were the most widely grown cultivars under the rain-fed conditions of the Central Anatolian Plateau (CAP), covering about $40 \%$ of total wheat cultivated land of Turkey (Table 1).

Among the genotypes G6-G20, the advanced inbred lines identified were those from the IWWIP (International Winter Wheat Improvement Program-http://www.iwwip.org), a joint program between Turkey, CIMMYT and ICARDA (Table 1).

\subsection{Climate and soil characteristics}

Soil conditions for conducting the field trials were suitable. During the crop cycle, temperature pattern was similar to that of the long term average. As for the precipitation pattern, it was totally different from that of the long term average; considering the total amount of precipitation during the whole crop cycle, it was lower than that of the long term average. As a consequence, the water deficit, difference between the cropping season and long term average of precipitation, caused a remarkable reduction in grain yield and quality traits (data not shown).

\subsection{Quality analysis}

Flour milling

The wheat grains were stored for $48 \mathrm{~h}$ at $14 \%$ moisture and milled using a Quadrumat Senior mill (Brabender, Germany). Flours of approximately $65 \%$ extraction were used for further quality analyses (American Association of Cereal Chemists International, 2000).

\section{Wet gluten content (\%)}

Wet gluten content (WGC) was analyzed using a Glutomatic 2200 (Perten Instruments) according to American Association of Cereal Chemists International, (2000).

Protein content (\%)

Flour samples were evaluated for protein content (PC) using (American Association of Cereal Chemists International, 2000)

\section{Zeleny sedimentation volume $(m L)$}

Zeleny sedimentation volume (ZSV) was determined using (American Association of Cereal Chemists International, 2000)

Grain hardness (PSI)

(12)'s Near-Infrared Reflectance Method was used for grain hardness $(\mathrm{GH})$.
Test weight $(\mathrm{kg} / \mathrm{hL})$

Test weight (TW) was recorded as kilograms/hectoliter $(\mathrm{kg} / \mathrm{hL})$ based on (American Association of Cereal Chemists International, 2000).

\section{Thousand kernel weight $(g)$}

Thousand kernel weight (TKW) was recorded as grams/1000 kernels of cleaned wheat.

\subsection{SDS-PAGE analysis}

HMW-GS and LMW-GS were separated by sodium dodecyl-sulfate polyacrylamide gel electrophoresis (SDS-PAGE) based on the extraction method described by (Singh et al., 1991), with modifications reported by (Liu et al., 2005; He et al., 2005). The presence of the $1 \mathrm{~B} / 1 \mathrm{R}$ translocation was determined by SDS-PAGE of alcohol-soluble and alcohol insoluble protein extracts, detecting the presence of Sec-1 secalins in the first test and the presence of the Glu-B3j allele in the second test.

\subsection{Statistical analysis}

Variance (ANOVA) and Pearson's correlation analyses were performed using (SAS Institute Inc., 2004), and a comparison of the means was performed using the LSD test $(p<0.01)$ and the same software. Principal component and Biplot analyses were performed using Biplot and Singular Value Decomposition Macros for Excel $^{\odot}$ (Lipkovich \& Smith, 2002).

Broad sense heritability $(\mathrm{H})$ estimates were calculated according to (Singh \& Ceccarelli, 1996).

Table 1. Genotypes.

\begin{tabular}{cl}
\hline Code & \multicolumn{1}{c}{ Pedigree } \\
\hline G1 & GEREK-79 \\
G2 & KARAHAN-99 \\
G3 & SONMEZ-01 \\
G4 & MUFITBEY \\
G5 & BAYRAKTAR \\
G6 & VEE/TSI//GEREK/3/NS55.03/5/C126.15/COFN//6/TAM200/ \\
& KAUZ \\
G7 & BOEMA/ALTAY//ALTAY 2000 \\
G8 & AUS GS50AT34/SUNCO//CUNNINGHAM \\
G9 & SUNCO/2^PASTOR \\
G10 & BILINMEYEN96.7 \\
G11 & BURBOT-6 \\
G12 & VRATZA/3/ORF1.148/TDL//BLO/4/PONY/OPATA \\
G13 & TAM200/KAUZ/3/SPN/NAC//ATTILA/4/F885K1.1/SXL \\
G14 & ZCL/3/PGFN//CNO67/SON64(ES86-8)/4/KA../4/ \\
& BEZOSTAYA-1/NAD//KZM (ES85.24)/3/F900K \\
G15 & SHARK-1/3/INDIANDWARF/KORB DOLI//DUKATI \\
G16 & CHIRYA.3/GK OTHALON \\
G17 & VORONA/PARUS//HATUSHA/3/LUT112/4/PEHL//RPB8- \\
& 68//CHRC \\
G18 & ALAMOOT/CATBIRD \\
G19 & OVERLEY*3/AMADINA \\
G20 & VEE\#8//JUP/BJY/3/F3.71/TRM/4/BCN/5/KAUZ/6/163 \\
\hline &
\end{tabular}




\section{Results}

\subsection{Genotype $(G)$ means and ranges over the environments studied (E)}

G means and ranges were calculated for GY and quality characteristics (Table 2). In general, Gs had relatively low GY (range 2.26-3.05 t/ha, mean $=2.71 \mathrm{t} / \mathrm{ha}$ ), and PC (range 10.1-13.2 \%, mean $=11.6 \%)$. WGC and ZSV were moderate (range $28-37 \%$, mean $=32 \%)($ range $24-33 \mathrm{~mL}$, mean $=29 \mathrm{~mL}$, respectively). $\mathrm{GH}$ had medium soft hardness, ranging from 48 to 60 PSI with mean $=55$ PSI. TKW ranged from $28 \mathrm{~g}$ to $33 \mathrm{~g}($ mean $=30 \mathrm{~g})$ and $\mathrm{TW}$ varied from 76 to $82 \mathrm{~kg} / \mathrm{hL}$ $($ mean $=79 \mathrm{~kg} / \mathrm{hL})$.

Generally speaking, genotypes with higher GY, TKW, and TW had inferior quality values (e.g. G1, G3, G19 and G20) or vice versa. Comparing the means of quality traits of the genotypes tested, it can be said that G4, G5, G7, G8, G9, G12, G13, and G14 had better quality values than those of the other genotypes (Table 2).

\subsection{Genotype $x$ Environment Interaction (GEI)}

The influence of G, E, and GEI on GY and 6 quality traits was determined. Table 3 shows that G, E, and GEI had significant effects on all the traits analyzed. The $\mathrm{E}$ was the main factor controlling GY, TKW, and TW, accounting for $70.2 \%, 78.5 \%$ and $63 \%$ of the total variance, respectively. In addition, most of the total variance in the remaining quality traits was determined partially by the E, along with G, and GEI also showed influence in defining PC, WGC, ZSV and GH. Therefore, the effects of $\mathrm{E}$ and the GEI cannot be ignored when breeding wheat for end-use quality.

\subsection{Broad Sense Heritability $(H)$}

$H$ values estimated for traits of interest are given in Table 3. $\mathrm{H}$ ranged from 0.32 , for TKW, to 0.52 , for $Z$ SSV. The $H$ values ranged from low to moderate values for all of the characteristics studied due to larger E variance (with GEI), indicating the $\mathrm{E}$ effect. $\mathrm{H}$ values for PC, WGC, ZSV, and TW were relatively larger than those of GY, GH, and TKW. The $H$ values for the GY were $0.45,0.41,0.52$, and 0.42 , whereas for the TWK they were $0.33,0.34$, and 0.32 , respectively.

\subsection{High Molecular Weight Glutenin Subunites (HMW-GS)}

The loci and allele's numbers and frequencies of HMW-GS observed in the 20 genotypes are shown in Table 4 . A total of 8 alleles at the Glu-1 loci were detected among the genotypes examined. Two alleles were observed at the locus Glu-A1, among which the subunit $2^{\star}$ (allele b) was most frequent with the frequency of $65 \%$. The frequency of subunit 1 (allele a) was $35 \%$. Four alleles were present at the locus Glu-B1. Subunit combinations $7+9$ (allele c) and $7+8$ (allele b) had high frequencies of 35 and $50 \%$, respectively, followed by subunit 7 (allele a) (10\%) and 17+18 (allele i) (5\%). SDSPAGE differentiated 2 alleles at the locus Glu-D1. Subunit combinations $2+12$ (allele a) and 5+10 (allele $\mathrm{d}$ ) were almost equally dominant with the frequencies of 55 and $45 \%$, respectively (Table 4 ).

Table 2. Means of grain yield and quality traits of genotypes in the environments studied.

\begin{tabular}{|c|c|c|c|c|c|c|c|}
\hline Genotype & $\mathrm{GY}^{\dagger}$ & $\mathrm{PC}$ & WGC & ZSV & $\mathrm{GH}$ & TKW & TW \\
\hline$G 1^{*}$ & 2.96 & 10.1 & 28 & 27 & 56 & 32 & 81 \\
\hline G2 & 2.50 & 12.0 & 30 & 26 & 55 & 29 & 80 \\
\hline G3 & 2.95 & 10.2 & 29 & 27 & 50 & 30 & 82 \\
\hline G4 & 2.82 & 13.2 & 33 & 28 & 48 & 32 & 79 \\
\hline G5 & 2.90 & 11.2 & 31 & 29 & 52 & 32 & 79 \\
\hline G6 & 2.55 & 10.9 & 30 & 32 & 60 & 28 & 77 \\
\hline G7 & 2.70 & 12.0 & 33 & 28 & 54 & 30 & 78 \\
\hline G8 & 2.50 & 13.0 & 32 & 33 & 50 & 30 & 79 \\
\hline G9 & 2.68 & 13.0 & 33 & 32 & 55 & 30 & 79 \\
\hline G10 & 2.75 & 11.2 & 31 & 29 & 52 & 32 & 78 \\
\hline G11 & 2.83 & 11.0 & 35 & 28 & 60 & 32 & 77 \\
\hline G12 & 2.63 & 12.0 & 33 & 30 & 56 & 29 & 79 \\
\hline G13 & 2.52 & 12.0 & 36 & 33 & 55 & 30 & 80 \\
\hline G14 & 2.51 & 13.0 & 35 & 32 & 58 & 32 & 76 \\
\hline G15 & 2.68 & 12.0 & 37 & 29 & 56 & 28 & 80 \\
\hline G16 & 2.62 & 10.2 & 31 & 30 & 60 & 29 & 79 \\
\hline G17 & 2.95 & 10.1 & 29 & 26 & 50 & 30 & 77 \\
\hline G18 & 2.26 & 10.7 & 28 & 26 & 56 & 29 & 75 \\
\hline G19 & 2.82 & 13.0 & 29 & 26 & 58 & 33 & 78 \\
\hline G20 & 3.05 & 11.6 & 30 & 24 & 60 & 29 & 81 \\
\hline Mean & 2.71 & 11.6 & 32 & 29 & 55 & 30 & 79 \\
\hline $\operatorname{LSD}_{(0.01)}$ & 0.46 & 0.55 & 1.42 & 1.89 & 2.56 & 1.21 & 2.45 \\
\hline
\end{tabular}

${ }^{\dagger}$ GY, Grain yield (t/ha); PC, Protein content (\%); WGC, Wet gluten content (\%) ZSV, Zeleny sedimentation volume (mL); GH, Grain hardness (PSI); TKW, Thousand kernel weight (g) TW; Test weight $(\mathrm{kg} / \mathrm{hL}) ;{ }^{\ddagger} \mathrm{G}$, Genotype. 
Table 3. ANOVA and G, E, and GEI variances for grain yield and quality traits across environments.

\begin{tabular}{|c|c|c|c|c|c|c|c|c|c|}
\hline & \multicolumn{3}{|c|}{ Mean Square } & \multicolumn{3}{|c|}{ Variance $(\%)^{¥}$} & \multirow[b]{2}{*}{$\mathrm{CV}$} & \multirow[b]{2}{*}{$\mathrm{R}^{2}$} & \multirow[b]{2}{*}{$\mathrm{H}$} \\
\hline & $\mathrm{G}^{\ddagger}$ & $\mathrm{E}$ & GEI & $\mathrm{G}$ & $E$ & GEI & & & \\
\hline $\mathrm{GY}^{\dagger}$ & $16.83^{\star *}$ & $660.31^{\star *}$ & $6.35^{\star *}$ & 17.0 & 70.2 & 12.8 & 15.68 & 0.81 & 0.33 \\
\hline $\mathrm{PC}$ & $6.84^{* *}$ & $80.12^{\star *}$ & $1.84^{\star *}$ & 36.1 & 44.4 & 19.4 & 6.55 & 0.87 & 0.45 \\
\hline ZSV & $422.33^{\star *}$ & $5061.25^{\star *}$ & $85.61^{\star *}$ & 37.5 & 47.3 & 15.2 & 7.54 & 0.89 & 0.52 \\
\hline $\mathrm{GH}$ & $802.43^{\star *}$ & $10177.31^{\star *}$ & $316.71^{\star *}$ & 32.0 & 42.7 & 25.2 & 12.30 & 0.81 & 0.34 \\
\hline
\end{tabular}

${ }^{* *}<0.01 ;{ }^{\dagger} \mathrm{GY}$, Grain yield (t/ha); PC, Protein content (\%); WGC, Wet gluten content (\%); ZSV, Zeleny sedimentation volume (mL); GH, Grain hardness (PSI); TKW, Thousand kernel weight (g); TW, Test weight (kg/hL); ${ }^{\ddagger} \mathrm{G}$, Genotype; E, Environment; GEI, Genotype x environment interaction; $\mathrm{CV}_{(\%)}$, Coefficient of variation; $\mathrm{R}^{2}$, Coefficient of determination; $\mathrm{H}$, Broad sense heritability; ${ }^{\vee}$ Variance (\%), ration of G, E, GEI SS to sum of G, E, GEI SS

Table 4. Allele numbers (\#) and frequencies (F) and statistical analysis of the effects of HMW-GS and LMW-GS on grain yield and quality traits.

\begin{tabular}{|c|c|c|c|c|c|c|c|c|c|c|}
\hline Locus & Subunit & \# & $\mathrm{F}(\%)$ & $\mathrm{GY}^{\dagger}$ & PC & WGC & ZSV & $\mathrm{GH}$ & TKW & TW \\
\hline \multirow[t]{2}{*}{ Glu-A1 } & 1 & 7 & 35 & 2.73 & 12 & 32 & 29 & 54 & 30 & 79 \\
\hline & $2^{*}$ & 13 & 65 & 2.70 & 11 & 31 & 28 & 56 & 30 & 79 \\
\hline \multirow[t]{4}{*}{ Glu-B1 } & 7 & 2 & 10 & 2.74 & 11 & 33 & 30 & 53 & 30 & 81 \\
\hline & $7+8$ & 10 & 50 & 2.69 & 12 & 32 & 29 & 55 & 30 & 79 \\
\hline & $7+9$ & 7 & 35 & 2.72 & 11 & 31 & 28 & 56 & 30 & 78 \\
\hline & $17+18$ & 1 & 5 & 2.70 & 12 & 33 & 28 & 54 & 30 & 78 \\
\hline \multirow[t]{2}{*}{ Glu-D1 } & $5+10$ & 9 & 45 & 2.63 & 12 & 33 & 30 & 55 & 30 & 79 \\
\hline & $2+12$ & 11 & 55 & 2.80 & 11 & 30 & 28 & 55 & 30 & 78 \\
\hline \multirow[t]{6}{*}{ Glu-A3 } & $\mathrm{a}$ & 3 & 15 & 2.74 & 11 & 32 & 28 & 56 & 31 & 79 \\
\hline & b & 4 & 20 & 2.59 & 13 & 34 & 32 & 55 & 30 & 79 \\
\hline & c & 7 & 35 & 2.78 & 11 & 31 & 28 & 54 & 31 & 79 \\
\hline & d & 3 & 15 & 2.71 & 12 & 32 & 30 & 58 & 29 & 79 \\
\hline & e & 2 & 10 & 2.54 & 12 & 29 & 26 & 57 & 31 & 76 \\
\hline & $\mathrm{f}$ & 1 & 5 & 2.95 & 10 & 29 & 26 & 50 & 30 & 77 \\
\hline \multirow[t]{6}{*}{ Glu-B3 } & b & 5 & 25 & 2.60 & 12 & 35 & 29 & 56 & 29 & 79 \\
\hline & e & 7 & 35 & 2.90 & 11 & 33 & 28 & 56 & 30 & 79 \\
\hline & $\mathrm{f}$ & 1 & 5 & 2.82 & 13 & 33 & 28 & 48 & 32 & 79 \\
\hline & g & 3 & 15 & 2.56 & 13 & 33 & 32 & 54 & 31 & 78 \\
\hline & $\mathrm{h}$ & 1 & 5 & 2.75 & 11 & 31 & 29 & 52 & 32 & 78 \\
\hline & j & 3 & 15 & 2.68 & 11 & 29 & 26 & 55 & 31 & 77 \\
\hline \multirow[t]{4}{*}{ Glu-D3 } & $\mathrm{a}$ & 5 & 25 & 2.73 & 12 & 32 & 29 & 52 & 31 & 79 \\
\hline & b & 7 & 35 & 2.72 & 12 & 31 & 29 & 57 & 31 & 79 \\
\hline & c & 7 & 35 & 2.74 & 11 & 32 & 28 & 55 & 30 & 79 \\
\hline & d & 1 & 5 & 2.26 & 11 & 28 & 26 & 56 & 29 & 75 \\
\hline \multirow[t]{2}{*}{$1 \mathrm{~B} / 1 \mathrm{R}$} & - & 17 & 85 & 2.71 & 12 & 32 & 29 & 55 & 30 & 79 \\
\hline & + & 3 & 15 & 2.68 & 11 & 29 & 26 & 55 & 31 & 77 \\
\hline LSD (0.05) & & & & 0.41 & 0.85 & 1.58 & 1.91 & 2.45 & 1.35 & 2.54 \\
\hline
\end{tabular}

${ }^{\dagger}$ GY, Grain yield (t/ha); PC, Protein content (\%); WGC, Wet gluten content (\%); ZSV, Zeleny sedimentation volume (mL); GH, Grain hardness (PSI); TKW, Thousand kernel weight (g); TW, Test weight $(\mathrm{kg} / \mathrm{hL})$.

\subsection{Low Molecular Weight Glutenin Subunites (LMW-GS)}

The loci and allele's numbers and frequencies of LMW-GS observed in the 20 genotypes are shown in Table 4 . A total of 16 alleles at the Glu-3 loci were detected among the genotypes examined. Six alleles were observed at the locus Glu-A3, among which the subunit Glu-A3's two alleles (b and c) were most frequent with the frequencies of 20 and $35 \%$, respectively. Six alleles were present at the locus Glu-B3. Among them, alleles $\mathrm{b}$ and e located on Glu-B3 locus had high frequencies of 25 and $35 \%$, respectively, followed by allele g (15\%) and allele $\mathrm{j}(15 \%)$. Alleles $\mathrm{f}$ and $\mathrm{h}$ had low frequencies of $5 \%$. Four alleles were detected on the locus Glu-D3. Alleles b and c were equally dominant with the frequencies of $35 \%$. Allele a had also relatively high frequency of $25 \%$.

\subsection{B/1R translocations}

Among all genotypes, merely G17, G18 and G19 (15\%) contained $1 \mathrm{~B} / \mathrm{lR}$ translocation. Comparing the means of the quality traits of the $1 \mathrm{~B} / 1 \mathrm{R}$ translocated genotypes with those of the non $1 \mathrm{~B} / 1 \mathrm{R}$ translocated genotypes; the means of the 
quality traits of the $1 \mathrm{~B} / 1 \mathrm{R}$ translocated genotypes were low, indicating that $1 \mathrm{~B} / 1 \mathrm{R}$ translocations affected the quality traits adversely (Table 4).

\subsection{Relationships between grain yield (GY) and quality traits}

GY was significantly positively correlated $(r=0.511$, $\mathrm{p}<0.05)$ with TW, but negatively correlated with ZSV $(r=-0.485$, $\mathrm{p}<0.05)$. It was also negatively correlated with PC, WGC, and $\mathrm{GH}$, but positively correlated with TKW. However, they were not statistically significant.

PC showed a significant positive correlation with WGC $(\mathrm{r}=0.498, \mathrm{p}<0.05)$, whereas it was positively correlated with ZSV although the relationship was statistically non-significant.

WGC did not show any significant relationship with GH, TKW, and TW; however, it was positively correlated with ZSV $(\mathrm{r}=0.565, \mathrm{p}<0.01)$.

\subsection{Biplot analysis}

Biplot analysis was used to examine the relationships between the genotypes and GY together with quality traits (Figure 1). The first two PCs (principal components 1 and 2 ) accounted for $55 \%(\mathrm{PC} 1=33 \%$ and $\mathrm{PC} 2=22 \%)$ of the relationships between the genotypes and all of the traits. PC, WGC, and ZSV were grouped on the positive PC1 axis of the biplot, suggesting strong relationships among them. Therefore, they were called protein related traits.

Like PC, WGC, and ZSV, the genotypes G7, G8, G9, G12, G13, G14, and G15 were also grouped on the positive PC1 axis.
Therefore, it was suggested that these genotypes showed similar responses for PC, WGC, and ZSV in the environments.

Unlike the protein related traits, GY, TKW, and TW were grouped on the negative PC1 axis of the biplot, suggesting strong relationships among them. Thus, they were called yield related traits.

Like GY, TW and TKW, the genotypes G3, G4, G5, G10, and G19 were also grouped on the negative PC1 axis. Therefore, it was suggested that those showed similar responses for GY, TW, and TKW across environments.

\section{Discussion}

\subsection{Genotype $x$ environment interaction (GEI) and Broad sense heritability $(H)$}

GY and quality traits were affected more intensely by the $\mathrm{E}$ than by the $\mathrm{G}$, and GY, GH, and TKW reacting more expressively to the changes in $\mathrm{E}$ than to changes in PC, WGC, ZSV, and TW. PC was one of the most responsive traits since it was predominantly affected by E and GEI (Williams et al., 2008). It appears that GEI effects, although significant, were lower than the effects of $\mathrm{G}$ and $\mathrm{E}$, for all of the traits (Mladenov et al., 2001).

$\mathrm{H}$ of a trait is important since it determines the response to selection (Sharma \& Smith, 1986). The magnitude of $\mathrm{H}$ was affected by the type of genetic material and yield level of the environment due to the fact that the studied characters are created by the effects of genes and growing seasons. In the present study, Hs for GY was examined, and the quality traits varied from low to moderate (Baker et al., 1971).

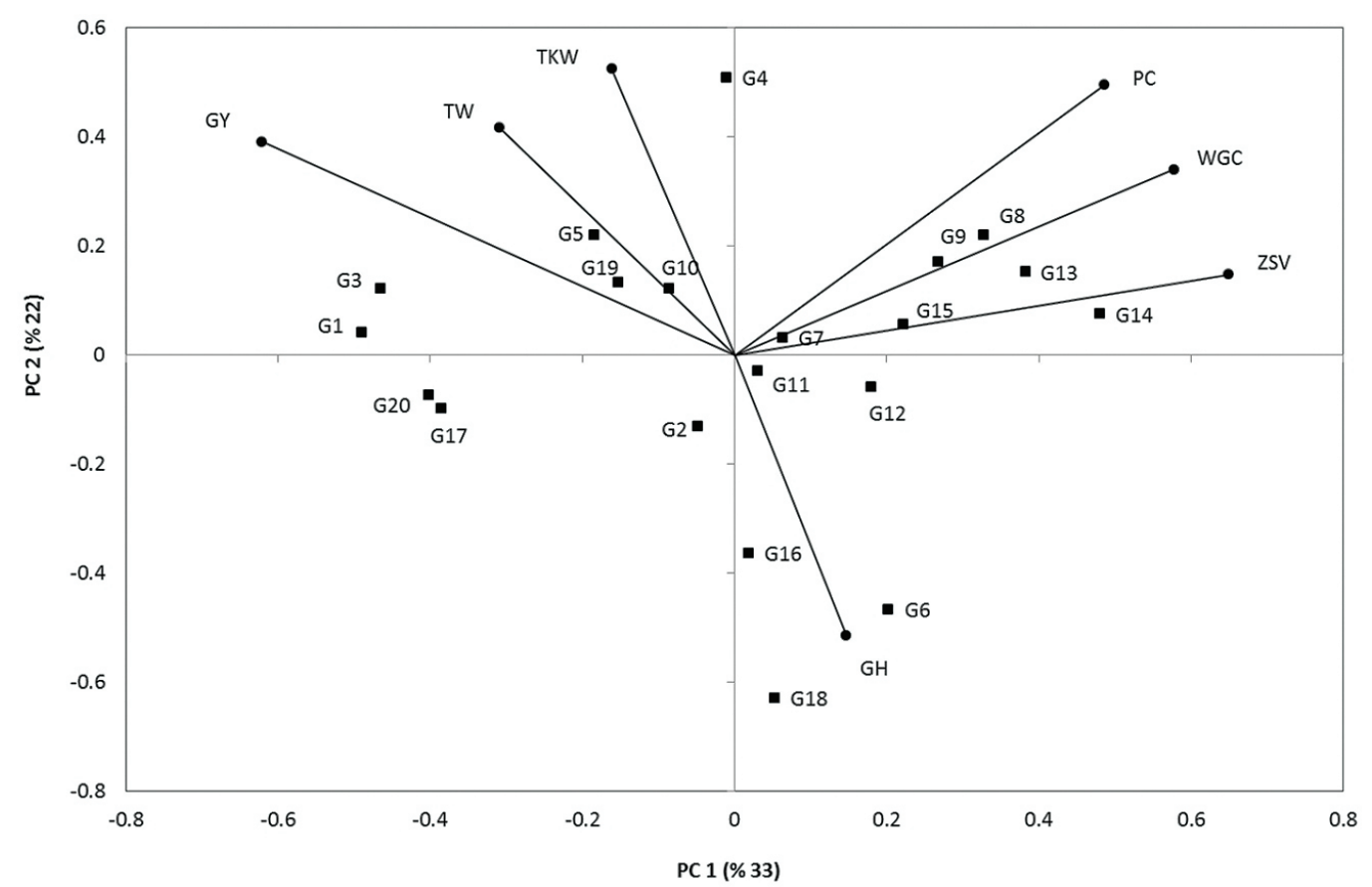

Figure 1. Biplot analysis for grain yield and quality traits. GY, Grain yield (t/ha); PC, Protein content (\%); WGC, Wet gluten content (\%); ZSV, Zeleny sedimentation volume (mL); GH, Grain hardness (PSI); TKW, Thousand kernel weight (g); TW, Test weight (kg/hL); G, Code for genotypes. 
Selection for PC in wheat is affected by the negative relationship with GY. Our results were in agreement with those reported by (Clarke et al., 2000). In addition, Klatsikes \& Lee (1971) found low H for TKW. Although ZSV was widely used in early generation selection parameters for bread wheat, $\mathrm{H}$ for ZSV is low in this study. Like our results, $\mathrm{H}$ for ZSV varies from intermediate to high values in wheat (Clarke et al., 2000; Akcura, 2009). Barnard et al. (2002) determined medium-high $\mathrm{H}$ for PC, ZSV, TW and TKW and reported that a successful and rapid selection with respect to quality criteria may be in question only for the characters with high heritability. Zanetti et al. (2001) determined high $\mathrm{H}$ for PC and TKW. The same researchers suggested that the GY and PC seem to be controlled by genotypes more than by the environment in comparison with test weight. The heritability estimated in our study was much lower than that estimated in the study conducted by (Zanetti et al., 2001).

In the present study, $\mathrm{H}$ for GY was low. Sharma \& Smith (1986) reported that GY was highly influenced by the E and is known to have low $\mathrm{H}$. The most common justification for conducting selection in optimum environments, regardless of the nature of the target environment, was the lower $\mathrm{H}$ found by (Ceccarelli, 1994) in low yielding Es. Furthermore, Ceccarelli (1996) reported that a lower $\mathrm{H}$ value was expected in low input conditions. In the present study, low estimates of heritability were observed for grain yield and quality traits. Akcura (2009) also reported moderate to low values of $\mathrm{H}$ for GY in wheat.

\subsection{High and low molecular weight glutenin subunits (HMW-GS and LMW-GS) and 1B/1R translocation}

In this study, the effect of subunit 1 , being significantly higher than $2^{\star}$ in the genotypes, at Glu-A1 on quality was better, in agreement with results of other studies (Payne et al., 1984; Liu et al., 2005). Subunit 1 expressed higher values for PC, WGC, and ZSV than those of $2^{\star}$. However, the effect of subunit $2^{\star}$ on quality was divergent.

Glu-B1 locus subunits $17+18$ and $7+8$ had positive effects on PC, WGC, and ZSV determined in the present study. Payne et al. (1987) ranked Glu-B1 subunits in descending order of baking quality as $17+18,7+8,7+9,6+8$, and 7 .

Glu-D1d $(5+10)$ is a HMW-GS allele conferring better quality (Guo et al., 2010). Positive effect of Glu-D1d was present on the genotypes used in this study. Sultana et al. (2007) screened some Pakistani wheat varieties for HMW-GS allele and Glu-D1d $(5+10)$ using SDS-PAGE and found similar results to those of the present study.

Payne et al. (1987) found that, in general, genotypes containing HMW-GSs 5+10 have higher quality compared with that of genotypes containing $2+12$. In this study, such conclusion could be drawn for the examined genotypes and the analyzed traits. Taking Glu-D1 locus subunits into consideration, $5+10$ showed the best average mean for PC, WGC, ZSV, and TW, but lower values for $2+12$, which is in agreement with the results of the authors mentioned above. It has been proved that the subunits designated as: Glu A1-1, Glu A1 (2*), Glu B1 $(7+9)$, Glu B1 $(17+18)$, or Glu D1 $(5+10)$ are related to high technological quality, whereas their allelic variants such as Glu A1 (null), Glu B1 $(6+8)$, or Glu D1 $(2+12)$ are related to lower quality (Gianıbell et al., 2001). Judging by the HMW-GS composition, only one genotype (G7) is expected to have good quality, due to the presence of subunits $2^{\star}, 5+10$, and $17+18$ (Payne et al., 1987).

In our study, there was no significant increase in GY, comparing non $1 \mathrm{~B} / 1 \mathrm{R}$ translocated genotypes with the translocated ones. The translocation was associated with lower PC, WGC, ZSV, and higher TW. Therefore, it negatively affected most of the quality traits. Several reports, however, have reported that some genotypes with translocation might have good dough quality (Bullrich et al., 1998).

LMW-GS encoded by Glu-B3 allele plays a key role in gluten strength (Flaete \& Uhlen, 2003). Zhang et al. (2008) reported that genotypes with positive allele of $1 \mathrm{~B} / 1 \mathrm{R}$ are negative for Glu-B3 allele. In our study, the positive allele of Glu-B3 was present in $85 \%$ wheat genotypes, whereas $15 \%$ of the genotypes did not have this allele. Our results also revealed a positive association between Glu-B3 and PC, WGC, and ZSV. This indicates that the marker assisted selection for Glu-B3 can be useful to select genotypes with desirable PC, WGC, and ZSV.

In our study, Glu-A3b, Glu-B3b, and Glu-D3b were LMW-GS alleles, which exert a positive effect on PC, WGC, and ZSV. Cornish et al. (1993) found that the Glu-3 composition b, b, b (at loci Glu-A3, Glu-B3 and Glu-D3, respectively) gave the best extensibility. They also reported that Glu-A3e, Glu-B3c, d, and g alleles were associated with medium to weak dough properties. However, the contribution of alleles encoding LMW-GSs to quality also varies (Eagles et al., 2006).

\subsection{Biplot and correlation analyses}

The biplot analysis indicated that the traits studied were clustered into two groups. Like the traits, the genotypes studied were also seperated into the two groups. These results are in agreement with those of (Saint P1erre et al., 2008), which indicated that the grouping of genotypes in the biplot showed that the genotypes within the quality groups reacted similarly to the combinations of the quality traits.

In general, the genotypes containing HMW-GSs $2^{*}, 7+9$, $2+12$ were positioned exclusively on the negative side of the PC1 axis, while the genotypes containing $1,7+8,5+10$ were located on the positive side. Our findings were in agreement with the results of (Panozzo \& Eagles, 2000). Meanwhile, relatively higher yielding genotypes, with the subunits $2^{*}, 7+9$, and $2+12$ were located on the negative PC1 axis, while relatively lower yielding genotypes, with the subunits $1,7+8$, and $5+10$ were positioned on the positive PC1 axis. It may be concluded that genes confering GY could be negatively associated with genes determining protein quantity and quality for genotypes used in this study.

Traits of wheat may be correlated to each other in a positive or a negative manner. The direction of the correlation is independent of the breeding objectives and may change from one production environment to another. GY and PC 
are negatively correlated with each other (O'Brien \& Ronalds, 1987). This negative relationship between GY and PC is highly undesirable for the development of cultivars eligible for grades of the market class (Depauw et al., 2007).

The association between ZSV and PC was highly significant, which was expected since the influence of PC on the ZSV is well known. ZSV is significantly influenced by PC, and the magnitude of the effect varies according to the genotype (Cubadda et al., 2007).

The negative correlation between ZSV and GY was highly significant. This is in accordance with other reports (Cubadda et al., 2007). This is probably also linked to the highly significant correlation of ZSV with PC, in which high PC is known to be negatively associated with GY.

\section{Conclusion}

The present study showed that GY and quality traits were determined mainly by $\mathrm{E}$, whereas the influence of $\mathrm{G}$ is of less importance. GEI was of smaller size compared to G and E in terms of all the studied quality parameters. The majority of advanced breeding lines had low quality values for all environments. Negative association between high yield and good quality should be an important target for the next breeding efforts.

\section{Acknowledgements}

We would like to thank Dr. R. J. PENA from CIMMYT for conducting the SDS PAGE analysis. We would also like to thank Fatih OZDEMIR, IWWIP Coordinator from Turkey, Dr. Alex MORGUNOV, IWWIP Coordinator from CIMMYT, and Dr. Mesut KESER, IWWIP Coordinator from ICARDA for sharing the IWWIP wheat breeding material. We are very greatful to the Plant Breeding and Genetics Department for conducting the field trials and the Quality Department of Bahri Dagdas International Agricultural Research Institute, Turkey, for conducting quality analyses.

\section{References}

O’Brien, L., \& Ronalds, J. A. (1987). Heritabilities of small scale and standard measures of wheat quality for early generation selection. Australian Journal of Agricultural Research, 38(5), 801-808. http:// dx.doi.org/10.1071/AR9870801

Akcura, M. (2009). Genetic variability and interrelationship among grain yield and some quality traits in Turkish winter durum wheat landraces. Turkish Journal of Agriculture and Forestry, 33, 547-556.

American Association of Cereal Chemists International. (2000). AACC approved methods (10th ed.). Minnesota.

Baker, R. J., Tipples, K. H., \& Campbell, A. B. (1971). Heritabilities of and correlations, among quality traits in wheat. Canadian Journal of Plant Science, 51(6), 441-448. http://dx.doi.org/10.4141/cjps71-089

Barnard, A. D., Labuschagne, M. T., \& Van Niekerk, H. A. (2002). Heritability estimates of bread wheat quality traits in The Western Cape Province of South Africa. Euphytica, 127(1), 115-122. http:// dx.doi.org/10.1023/A:1019997427305

Branlard, G., \& Dardevet, M. (1985). Diversity of grain proteins and bread wheat quality. Correlation between high-molecular-weight subunits of glutenin and flour quality characteristics. Journal of Cereal Science, 3(4), 345-354. http://dx.doi.org/10.1016/S07335210(85)80007-2

Bullrich, L., Tranquilli, G., Pfluger, L. A., Suarez, E., \& Barneix, A. J. (1998). Bread-making quality and yield performance of 1BL/1RS wheat isogenic lines. Plant Breed, 117(2), 119-122. http://dx.doi. org/10.1111/j.1439-0523.1998.tb01463.x

Ceccarelli, S. (1994). Specific adaptation and breeding for marginal conditions. Euphytica, 77(3), 205-219. http://dx.doi.org/10.1007/ BF02262633

Ceccarelli, S. (1996). Adaptation to low/high input cultiva tion. Euphytica, 92(1-2), 203-214. http://dx.doi.org/10.1007/BF00022846

Clarke, J. M., Clarke, F. R., Ames, N. P., McCaig, T. N., \& Knox, R. E. (2000). Evaluation of predictors of quality for use in early generation selection. In C. Royo, M. M. Nachit, N. Di Fonzo \& J. L. Araus (Eds.), Durum wheat improvement in the Mediterranean region: new challenges (pp. 439-446). Zaragoza: CIHEAM. Serie A. Séminaires Méditerranéennes 40.

Cornısh, G. B., Burridge, P. M., Palmer, G. A., \& Wrigley, C. W. (1993). Mapping the origins of some HMW and LMW glutenin subunit alleles in Australian germplasm. In Proceedings of the 42nd Australian Cereal Chemistry Conference, Sydney.

Cubadda, R. E., Carcea, M., Marconi, E., \& Trivisonno, M. C. (2007). Influence of protein content on durum wheat gluten strength determined by the SDS sedimentation test and by other methods. Cereal Foods World, 52(1), 273-277.

Depauw, R. M., Knox, R. E., Clarke, F. R., Wang, H., Fernandez, M. R., Clarke, J. M., \& Mccarg, T. N. (2007). Shifting undesirable correlations. Euphytica, 157(3), 409-415. http://dx.doi.org/10.1007/ s10681-007-9379-5

Eagles, H. A., Cane, K., Eastwood, R. F., Hollamby, G. J., Kuchel, H., Martin, P. J., \& Cornısh, G. B. (2006). Contributions of glutenin and puroindoline genes to grain quality traits in southern Australian wheat breeding programs. Australian Journal of Agricultural Research, 57(2), 179-186. http://dx.doi.org/10.1071/AR05242

Flaete, N. E. S., \& Uhlen, A. K. (2003). Association between allelic variation at the combined Gli-1, Glu-3 Loci and Protein Quality in Common Wheat (Triticum aestivum L.). Journal of Cereal Science, 37(2), 129-137. http://dx.doi.org/10.1006/jcrs.2001.0447

Fowler, D. B., \& De La Roche, I. A. (1975). Wheat quality evaluation. 3. Influence of genotype and environment. Canadian Journal of Plant Science, 55(1), 263-269. http://dx.doi.org/10.4141/cjps75-037

Gaines, C. S. (1991). Associations among quality attributes of red and white soft wheat cultivars across locations and crop years. Cereal Chemists, 68(1), 56-59.

Gianıbellı, M. C., Gupta, R. B., Lafiandra, D., Margıtta, B., \& Macritchie, F. (2001). Polymorphism of high Mr glutenins in Triticum tauschii: characterisation by chromatography and electrophoretic methods. Journal of Cereal Science, 33(1), 39-52. http://dx.doi.org/10.1006/jcrs.2000.0328

Guo, X., Junxian, G., Xiuquan, L., Xinming, Y., \& Lihui, L. (2010). Molecular characterization of two novel Glu-D1-encoded sub units from Chinese wheat (Triticum aestivum L.) land race and functional properties of flours possessing the two novel subunits. Genetic Resources and Crop Evolution, 57(8), 1217-1225. http:// dx.doi.org/10.1007/s10722-010-9561-9

Gupta, R. B., \& Shepherd, K. W. (1990). Two-step one-dimensional SDS-PAGE analysis of LMW subunits of glutelin. Theoretical and Applied Genetics, 80(2), 183-187. PMid:24220893. http://dx.doi. org/10.1007/BF00224384 
He, Z. H., Liu, L., Xia, X. C., Liu, J. J., \& Pena, R. J. (2005). Composition of HMW and LMW glutenin subunits and their effects on dough properties, pan bread, and noodle quality of Chinese bread wheats. Cereal Chemistry, 82(4), 345-350. http://dx.doi.org/10.1094/CC82-0345

Klatsikes, P. J., \& Lee, J. (1971). Quantitative inheritance in durum wheat. Canadian Journal of Genetics and Cytology, 13(2), 210-218.

Lin, C. S., \& Binns, M. R. (1994). Concepts and methods for analysing regional trial data for cultivar and location selection. Plant Breeding Reviews, 12, 271-279.

Lipkovich, I. A., \& Smith, E. P. (2002). Biplot and singular value decomposition macros for Excel@. Journal of Statistical Software, 7(5), 1-15.

Liu, L., He, Z., Yan, Z., Zhang, J., Xia, Y., \& Pena, R. J. (2005). Allelic variation at the Glu-1 and Glu-3 loci, presence of the $1 \mathrm{~B} .1 \mathrm{R}$ translocation, and their effects on mixographic properties in Chinese bread wheats. Euphytica, 142(3), 197-204. http://dx.doi. org/10.1007/s10681-005-1682-4

Mladenov, N., Przulj, N., Hristov, N., Djuric, V., \& Milovanovic, M. (2001). Cultivar-by-environment interactions for wheat quality traits in semiarid conditions. Cereal Chemistry, 78(3), 363-367. http://dx.doi.org/10.1094/CCHEM.2001.78.3.363

Nyquist, W. E. (1991). Estimation of heritability and prediction of selection response in plant populations. Critical Reviews in Plant Sciences, 10(3), 235-322. http://dx.doi. org/10.1080/07352689109382313

Panozzo, J. F., \& Eagles, H. A. (2000). Cultivar and environmental effects on quality characters in wheat. II. Protein. Australian Journal of Agricultural Research, 51(5), 629-636.

Payne, P. I., \& Lawrence, C. J. (1983). Catalogue of alleles for the complex gene loci, Glu-B1 and Glu-D1 which code for high molecular weight subunits of glutenin in hexaploid wheat. Cereal Research Communications, 11, 29-35.

Payne, P. I., Holt, L. M., Jackson, E. A., \& Law, C. N. (1984). Wheat storage protein: their genetics and their potential for manipulation by plant breeding. Philosophical Transactions of the Royal Society B, 304(1120), 359-371. http://dx.doi.org/10.1098/rstb.1984.0031

Payne, P. I., Nightingale, M. A., Krattiger, A. F., \& Holt, L. M. (1987). The relationship between HMW glutenin subunit composition and the bread-making quality of British-grown wheat varieties. Journal of the Science of Food and Agriculture, 40(1), 51-65. http://dx.doi. org/10.1002/jsfa.2740400108
Pena, R. J., Amaya, A., Rajaram, S., \& Mujeep-Kazi, A. (1990). Variation in quality of characteristics associated with some spring $1 \mathrm{~B} / 1 \mathrm{R}$ translocation wheats. Journal of Cereal Science, 12(2), 105-112. http://dx.doi.org/10.1016/S0733-5210(09)80092-1

Poehlman, J. M., \& Sleper, D. A. (2006). Breeding field crops (5th ed.). Wiley-Blackwell.

Saint Pierre, C., Peterson, C. J., Ross, A. S., Ohm, J. B., Verhoeven, M. C., Larson, M., \& Hoefer, B. (2008). Winter wheat genotypes under different levels of nitrogen and water stress: changes in grain protein composition. Journal of Cereal Science, 47(3), 407-416. http://dx.doi. org/10.1016/j.jcs.2007.05.007

SAS Institute Inc. (2004). What's new in $S A S^{\oplus}$ 9.0, 9.1, 9.1.2, and 9.1.3. Cary.

Sharma, R. C., \& Smith, E. L. (1986). Selection for high and low harvest index in three winter wheat populations. Crop Science, 26(6), 11471150. http://dx.doi.org/10.2135/cropsci1986.0011183X00260006 $0013 \mathrm{x}$

Singh, M., \& Ceccarelli, S. (1996). Estimation of heritability of crop traits from variety trial data. Aleppo: ICARDA. Technical Manual 21.

Singh, N. K., Shepherd, K. W., \& Cornısh, G. B. (1991). A simplified SDS-PAGE procedure for separating LMW subunits of glutenin. Journal of Cereal Science, 14(3), 203-208. http://dx.doi.org/10.1016/ S0733-5210(09)80039-8

Sultana, T., Ghafoor, A., \& Ashraf, M. (2007). Genetic variability in bread wheat (Triticum aestivum L.) of Pakistan based on polymorphism for high molecular weight Glutenin subunits. Genetic Resources and Crop Evolution, 54(6), 1159-1165.

Willıams, R. M., O’Brıen, L., Eagles, H. A., Solah, V. A., \& Jayasena, V. (2008). The influences of genotype, environment, and genotype $\mathrm{x}$ environment interaction on wheat quality. Australian Journal of Agricultural Research, 59(2), 95-111. http://dx.doi.org/10.1071/ AR07185

Zanetti, S., Winzeler, M., Feuillet, C., Keller, B., \& Messmer, M. (2001). Genetic analysis of breadmaking quality in wheat and spelt. Plant Breeding, 120(1), 13-19. http://dx.doi.org/10.1046/j.14390523.2001.00552.x

Zhang, P., He, Z., Zang, Y., Xıa, X., Chen, D., \& Zhang, Y. (2008). Association between \% SDS-unextractable polymeric proteins (\%UPP) and end-use quality in Chinese bread wheat cultivars. Cereal Chemistry, 85(5), 696-700. http://dx.doi.org/10.1094/ CCHEM-85-5-0696 